\title{
The Depressive Attributions Questionnaire (DAQ): Development of a Short Self-Report Measure of Depressogenic Attributions
}

\author{
Birgit Kleim • Désirée Gonzalo • Anke Ehlers \\ Published online: 29 May 2011 \\ (C) The Author(s) 2011. This article is published with open access at Springerlink.com
}

\begin{abstract}
A depressogenic attributional style, i.e., internal, stable and global causal interpretations of negative events, is a stable vulnerability factor for depression. Current measures of pessimistic attributional style can be timeconsuming to complete, and some are designed for specific use with student populations. We developed and validated a new short questionnaire suitable for the measurement of depressogenic attributions in clinical settings, the Depressive Attributions Questionnaire (DAQ). The 16-item DAQ, and measures of depression and related cognitive concepts were completed by three samples of depressed patients and matched controls, or depressed and non-depressed participants who had been exposed to a recent uncontrollable stressful life event (total $N=375$ ). The DAQ had high (i) internal reliability, (ii) test-retest reliability, (iii) convergent, discriminant and construct validity. It predicted a diagnosis of major depression at 6 months after an uncontrollable stressor, over and above what could be predicted from initial depression severity. Depressed patients rated the scale as acceptable. The DAQ may be a useful short measure of depressogenic attributions, which is easy to administer, and predicts concurrent and future depression. It
\end{abstract}

B. Kleim · A. Ehlers

King's College London, Institute of Psychiatry,

London, UK

Present Address:

B. Kleim $(\square)$

Department of Clinical Psychology and Psychotherapy,

Faculty for Psychology, University of Zurich,

Binzmuehlestrasse 14, Box 26, 8050 Zurich, Switzerland

e-mail: birgit.kleim@unibas.ch

Present Address:

D. Gonzalo

Psychology Department, University of New York in Prague,

Legerová 72 ,

12000 Prague, Czech Republic has possible applications as a screening measure for risk of depression, or as a treatment process measure.

Keywords Depression · Attribution · Cognition . Questionnaire · Assessment

Individuals who attribute uncontrollable negative life events to internal (caused by themselves), stable (unlikely to change) and global causes (likely to affect all areas of their life) have been shown to be more vulnerable to depression than those who tend to make external, unstable and specific attributions of negative events (Abramson et al. 1989). This pessimistic attributional style is a central hypothesis of the hopelessness theory of depression, which builds on earlier formulations of the learned helplessness theory of depression (Abramson et al. 1978; Seligman 1978) and overlaps with Beck's cognitive theory of depression (Beck 1967). People with a pessimistic attributional style are thought to be prone to develop generalised hopelessness, which, in turn, may lead to the common symptoms of depression. A number of studies have indeed confirmed a relationship between attributional style, hopelessness and concurrent and later depression in various samples, such as undergraduate students, adolescent psychiatric inpatients, or healthy participants at high versus low cognitive risk for depression (e.g., Alloy et al. 2006; Abramson et al. 1998; Gibb et al. 2001; Voelz et al. 2003; Hilsman and Garber 1995).

The main measure of pessimistic attributional style is the Attributional Styles Questionnaire (ASQ; Peterson et al. 1982). It is currently considered the "gold standard", along with its modified and expanded version, the Cognitive Style Questionnaire (CSQ; Haeffel et al. 2008). Both questionnaires present participants with hypothetical situations from achievement and affiliation domains (e.g., 'You have been looking for a job unsuccessfully for some time', or 'You meet a friend who acts hostilely towards you'), and ask them to generate one major cause for the situation and rate 
this cause on the dimensions internality, globality and stability. The ASQ indexes individual differences in internal, stable and global attributions in response to six negative and six positive vignettes, the CSQ contains twelve negative and twelve positive scenarios, and measures all three components of the cognitive vulnerability factor featured by the hopelessness theory of depression, namely, causal attributions, consequences and self-worth characteristics.

Further self-report instruments that have received somewhat less attention include the Expanded Attributional Style Questionnaire featuring 24 scenarios (EASQ; Peterson and Villanova 1988), the Attributional Style Assessment Test (ASAT; Anderson and Riger 1991), the Balanced Attributional Style Questionnaire (BASQ; Feather and Tiggemann 1984), and the Real Events Attributional Style Questionnaire (REASQ; Norman and Antaki 1988). Most of these are either specifically designed for student populations or have psychometric limitations.

The ASQ is therefore currently the instrument of choice for the assessment of depressogenic attributions in clinical populations. Despite its widespread use in contemporary clinical research, psychometric data regarding its reliability and validity remain sparse, and are mainly based on the original sample of 130 undergraduates (Peterson et al. 1982). Moreover, rating 12 scenarios may be too timeconsuming for many research and clinical settings.

A short-form of an instrument designed to measure pessimistic attributional style may thus be useful for clinical and research purposes. Of particular value would be an instrument that (i) is easy to complete, (ii) consists of items that are equally applicable to different participant groups, and (iii) reliably measures internal, stable, global attributions and helplessness. Here we describe the development of the Depressive Attributions Questionnaire (DAQ). We present item development and initial factor analyses, as well as data on reliability and validity in three independent studies, including a study of the DAQ's validity in predicting future major depression. Finally, we present data on participants' feedback on the DAQ and ASQ.

\section{Methods}

\section{Participants}

Participants from three separate studies were included. All studies were conducted at the Institute of Psychiatry, King's College London. Demographic and clinical sample characteristics are shown in Table 1.

Study $1(N=211)$ tested assault survivors at 2 weeks after receiving treatment for their injuries at an inner-city Emergency Department as part of a larger project (222 participants in total, Kleim et al. 2007). Participants who did not complete the DAQ $(n=11)$ did not differ from the remaining sample in terms of age, sex, ethnicity, years of education, marital status, depression symptom severity, all $p$ 's $>.286$. At 2 weeks, 43 participants $(20 \%)$ met criteria for major depression, as determined by the Structured Clinical Interview for DSM-IV (SCID; First et al. 1996). Six months later, 189 (89.6\%) participants were re-interviewed, and 33 $(15.6 \%)$ met criteria for major depression.

Study $2(N=85)$ recruited assault survivors who had been assaulted between 3 months and 15 months prior to the study from the same Emergency Department as those in Study 1, and via local advertisements. All participants completed the DAQ.

Study $3(N=79)$ recruited 26 patients with major depression from outpatient clinics based at the Maudsley Hospital and the Bethlem Royal Hospital, London, and 53 controls without depression from a participant database available at the Institute of Psychiatry. All completed the DAQ.

\section{Questionnaire Measures and Clinical Interview}

General Information Questionnaire This questionnaire was adapted from Halligan et al. (2003) to assess demographic characteristics (age, sex, ethnic background, marital status, education, socioeconomic status).

Depressive Attributions Questionnaire (DAQ) Details of the development of the 16 DAQ items are described below. The instructions were as follows. "Below is a list of statements dealing with how you generally feel about yourself and things that happen to you. Please circle the appropriate number to indicate how much you agree with each statement." Participants were asked to rate each item on a scale between 0 (not at all) and 4 (very strongly). Internal reliability of the total score in the present samples was $\alpha=.94$, inter-item correlation $r=.50$ (Study 1), .94, inter-item correlation $r=.51$ (Study 2), and .97, inter-item correlation $r=.64$ (Study 3).

Attributional Style Questionnaire Participants in Study 3 completed the ASQ (Peterson et al. 1982). The ASQ asks participants to generate the main cause for six hypothetical positive and six hypothetical negative life events and to indicate, on seven-point scales, the extent to which this cause is internal, stable, and global. For example, a rating of 1 on the internality/externality scale indicates that the event is totally due to other people or circumstances, while 7 reflects an event entirely caused by the participant. Mean scores were calculated separately for negative and positive events. Internal reliabilities were Cronbach's $\alpha=.86$ for negative events, inter-item correlation, $r=.26$, and $\alpha=.73$ for positive events, inter-item correlation, $r=.13$ (Study 3 ). 
Table 1 Demographic and clinical sample characteristics for each study sample ( $\mathrm{N}$ and percent or mean and standard deviation)

\begin{tabular}{|c|c|c|c|c|c|c|c|}
\hline \multirow{2}{*}{$\begin{array}{l}\text { Variable } \\
\text { Sex }\end{array}$} & \multirow[b]{2}{*}{ Male } & \multicolumn{2}{|c|}{ Study $1(n=211)$} & \multicolumn{2}{|c|}{ Study $2(n=85)$} & \multicolumn{2}{|c|}{ Study $3(n=79)$} \\
\hline & & 141 & 66.8 & 53 & 62.4 & 23 & 29.1 \\
\hline & Female & 70 & 33.2 & 32 & 37.6 & 56 & 70.9 \\
\hline Age & $M(S D)$ & \multicolumn{2}{|c|}{$34.65(11.38)$} & \multicolumn{2}{|c|}{$34.53(10.89)$} & \multicolumn{2}{|c|}{$37.58(11.05)$} \\
\hline \multirow[t]{2}{*}{ Ethnicity } & Caucasian & 122 & 57.8 & 51 & 60.0 & 59 & 74.7 \\
\hline & Black, mixed race, or other & 89 & 42.2 & 34 & 40.0 & 20 & 25.3 \\
\hline \multirow[t]{5}{*}{ Socio-economic status $^{\mathrm{a}}$} & Very low income (less than $£ 10,000$ ) & 90 & 42.7 & 39 & 45.9 & 23 & 29.1 \\
\hline & Low income $(£ 10,000-£ 20,000)$ & 48 & 22.8 & 12 & 14.1 & 13 & 16.5 \\
\hline & Moderate income $(£ 20,000-£ 40,000)$ & 37 & 17.5 & 16 & 18.8 & 34 & 43.0 \\
\hline & High income (over $£ 40.000$ ) & 24 & 11.3 & 10 & 11.8 & 9 & 11.4 \\
\hline & Refused information & 12 & 5.7 & 8 & 9.4 & 0 & 0 \\
\hline \multirow[t]{5}{*}{ Marital status } & Single & 142 & 67.3 & 55 & 64.7 & 52 & 65.8 \\
\hline & Married & 38 & 18.0 & 22 & 25.9 & 16 & 20.3 \\
\hline & Divorced/ separated & 25 & 11.8 & 8 & 9.4 & 10 & 12.7 \\
\hline & Widowed & 2 & .9 & 0 & 0 & 1 & 1.3 \\
\hline & Refused information & 4 & 1.9 & 0 & 0 & 0 & 0 \\
\hline Education & $M$ Years $(S D)$ & \multicolumn{2}{|c|}{$14.0(4.76)$} & \multicolumn{2}{|c|}{$14.45(7.28)$} & \multicolumn{2}{|c|}{$18.73(5.41)$} \\
\hline Number adult traumas & $M$ number (SD) & \multicolumn{2}{|c|}{$2.94(1.93)$} & \multicolumn{2}{|c|}{$5.20(2.47)$} & \multicolumn{2}{|c|}{$4.18(2.91)$} \\
\hline \multirow[t]{2}{*}{ Employment status } & Employed/ studying & 145 & 68.7 & 55 & 64.7 & 53 & 67.1 \\
\hline & Not employed & 66 & 31.3 & 30 & 35.3 & 26 & 32.9 \\
\hline \multirow[t]{2}{*}{ Concurrent depression } & Major depression (MD) & 43 & 20.4 & 19 & 22.4 & 26 & 32.9 \\
\hline & No major depression & 168 & 79.6 & 66 & 77.6 & 53 & 67.1 \\
\hline \multirow[t]{3}{*}{ Depression at 6 months } & Major depression (MD) & 33 & 15.6 & NA & & NA & \\
\hline & No major depression & 163 & 77.3 & & & & \\
\hline & Dropout & 15 & 7.1 & & & & \\
\hline
\end{tabular}

${ }^{\mathrm{a}}$ Combined household income

Beck Depression Inventory Severity of depression was assessed with the Beck Depression Inventory (BDI; Beck and Steer 1987), a widely used and validated standardized self-report measure of depression. Internal consistencies in the present studies were $\alpha=.91$, inter-item correlation, $r=.34$ (Study 1), .92, inter-item correlation, $r=.36$ (Study 2), and .90 , inter-item correlation, $r=.39$ (Study 3).

Posttraumatic Diagnostic Scale Severity of symptoms of posttraumatic stress disorder was assessed with the Posttraumatic Diagnostic Scale (PDS; Foa et al. 1997), a standardized and validated self-report measure of PTSD symptom severity that has been widely used with clinical and non-clinical samples of traumatized individuals. The PDS asks participants to rate 17 items regarding how much they were bothered by each of the PTSD symptoms specified in DSM-IV ranging from 0 (never) to 3 (5 times per week or more/very severely). Internal consistencies in the present studies were $\alpha=.93$, inter-item correlation, $r=.43$ (study 1), .94, , inter-item correlation, $r=.48$ (Study 2), and .96 , inter-item correlation, $r=.57$ (Study 3).
Hopelessness Scale A short form (4 items) of Beck's Hopelessness Scale (Beck and Steer 1988) compiled by Williams (2003) was used to assess hopelessness, i.e., participants' expectations about their future (e.g., "I am looking forward to the future with hope and enthusiasm") in Studies 1 and 2. Participants rated each item on a 4-point scale $(0=$ not at all, $3=$ very strongly $)$. Internal consistencies were $\alpha=.70$, inter-item correlation, $r=.37$ (Study 1), and .78, inter-item correlation, $r=.47$ (Study 2).

Self-Esteem Scale The Rosenberg Self-Esteem Scale (Rosenberg 1989) is a 10-item self-report measure of global self-esteem. It consists of 10 statements related to overall feelings of self-worth or self-acceptance, rated on a fourpoint scale ranging from strongly agree to strongly disagree. Internal consistencies in the present studies were $\alpha=.82$, inter-item correlation, $r=.31$ (Study 1), and .87, inter-item correlation, $r=.40$ (Study 2).

Trauma History As part of an interview about previous traumas, participants were asked whether they had experi- 
enced any traumatic event from a list of 11 events, such as a prior physical or sexual assault, motor vehicle accident, natural disaster, childhood physical or sexual abuse (adapted from Kubany et al. 2000).

Verbal Intelligence Participants completed the National Adult Reading Test (NART, Nelson 1991), a measure of verbal intelligence. The NART requires participants to read out aloud a list of 50 irregularly spelled words. The number of words read correctly comprises the final score. The NART has excellent reliability and construct validity, and correlates with other intelligence measures (Crawford et al. 1991; Nelson 1991).

Structured Clinical Interview Diagnoses of major depression were established with the Structured Clinical Interview for DSM-IV (SCID; First et al. 1996). In study 1, a trained clinical psychologist (BK) conducted the SCID for depression in a face-to-face interview at 2 weeks post-assault under the supervision of the senior author (AE). At 6 months, the depressionSCID module was administered over the telephone by the same interviewer. Cases were selected randomly for interrater reliability ratings, which were high $(\kappa=1$ for depression diagnosis; based on 56 interviews, 2 raters who were each uninformed as to the other rater's diagnoses). In study 2 and 3, two trained psychologists (BK, DG) conducted the face-to-face SCID depression module. Interrater reliability between the two raters was high ( $\kappa=.86$ for depression diagnosis).

Completion Duration and Feedback Form In Study 3, the duration for completing DAQ and ASQ was timed by the researcher. Participants also rated the perceived difficulty of the ASQ and DAQ, each on a rating scale from 1 to 10 , with 1 indicating 'not difficult', and 10 'very difficult'. To check the personal relevance of the ASQ's scenarios and the ability to draw from specific personal experiences, participants were also asked for how many of the hypothetical events they were able to find personal memories. Finally, an open-ended question asked participants to specify any difficulties they may have had during the completion of the questionnaires.

\section{Procedure}

The study was approved by the local ethics committees. Data collection took place in individual sessions at the Institute of Psychiatry, London, UK (all studies), or at Bethlem Royal Hospital (Study 3). All participants completed the DAQ, BDI, PDS and General Information Questionnaire, and the SCID major depression module. Participants in Studies 1 and 2 also completed the Short
Hopelessness Scale and Self-Esteem Scale. Participants in Study 1 were re-interviewed with the SCID major depression module at 6 months. In addition, participants in Study 3 completed the ASQ and the feedback form. They also filled in retest questionnaires (DAQ, BDI) 1 week after the research session, which they were asked to date and return in a freepost envelope. The mean test-retest period was 7.12 days, $S D=0.43$.

\section{Data Analyses}

Exploratory factor analyses using maximum likelihood estimation with oblimin rotation investigated the factor structure of the DAQ. Cronbach's $\alpha$ was calculated to determine the internal consistency of the DAQ, and Pearson correlations tested re-test reliability. Associations between DAQ and other scales and major depression diagnosis were examined with correlation and logistic regression analyses. Analyses were conducted with SPSS 15.0 and MPlus 5.0. Alpha levels were set to .05 for all analyses.

\section{Results}

\section{Item Development and Face Validity}

The development of the DAQ was guided by the hopelessness and learned helpnessness theories of depression (Abramson et al. 1978, 1989), and Beck's cognitive theory of depression (Beck et al. 1979). A new instrument was compiled that should rely less on the retrieval of specific scenarios and autobiographical events, which is often compromised in depression. The authors (BK, AE) as well as research clinical psychologists with extensive clinical experience in cognitive therapy generated questionnaire items following these theories, guided by the three proposed attributional dimensions of internal, stable and global attributions of negative events. Some additional items explicitly addressed perceived helplessness. Independent researchers and Aaron T. Beck reviewed an initial pool of 20 items. Feedback regarding item clarity, ambiguity, item overlap and theoretical coherence led to the selection of 17 items for the initial DAQ version. Instructions were also reviewed and some wordings rephrased.

Four patients in a psychiatric outpatient clinic filled in the initial 17-item version and gave feedback. The questionnaire was also rated by five expert clinicians. They judged all items, using a 10-point evaluation scale to rate the extent of each item's reflection of the respective dimension of depressogenic attribution. Ratings had a mean of 7.00 (range 5.94-8.92), indicating acceptable face validity for all items. Patients' feedback suggested good item comprehension, with exception of one item ("I will 
cause bad things in the future"), as this was not always well understood by patients and showed a comparatively low corrected item total correlation $(r=.63)$. It was thus excluded. This paper reports the results for the 16-item version. Four items assess internality/externality, 4 stability, 4 globality, and 4 perceived helplessness (see Appendix).

\section{Exploratory Factor Analyses}

Maximum likelihood estimation with oblimin rotation tested whether one, two or three factor solutions fit the DAQ data in the combined sample $(N=363)$ best (see Table 2). Based on previous studies, it was expected that attribution and helplessness dimensions would be either correlated or best be conceptualised as one single factor. We therefore selected oblimin, an oblique rotation procedure. The number of factors to be retained was determined by the number of eigenvalues $>1$, percentage of explained variance by factor, and by inspection of overall model fit. The latter was determined by examining fit indices (Bollen 1989; Kline 1998): normed chi-square, $\chi 2$ /degree of freedom ratio (CMIN/DF; values smaller than 2.0, 3.0, or 5.0 have been recommended as indicating good model fit in the literature), Tucker-Lewis Index (TLI; values larger than .90 are considered good fitting models), comparative fit index (CFI; values greater than .90 indicate good model fit), Akaike's information criterion (AIC), and root mean square error of approximation (RMSEA; values less than .10 indicate good model fit). As shown in Table 2, onefactorial, two-factorial and three-factorial models had a good fit with the data according to the fit indices. Only the one-factorial model had an eigenvalue above 1, explaining $56 \%$ of variance in depressogenic attributions in the data. Inspection of fit indices confirmed that the one-factor model fit the data well. According to the fit indices, the 2 and 3factorial solution also fit the data, but factors 2 and 3 explained only around $5 \%$ of the variance each, and had eigenvalues below 1 . We thus concluded that the 16-item DAQ is best conceptualised as one-dimensional. Internal consistency, validity and reliability will be reported for the 16-item one-dimensional scale. The resulting DAQ sumscore had a skewness of .90 , and a kurtosis of $.084, \mathrm{SD}=.251$, with a minimum score of 0 , and a maximum score of 68 .

Internal Consistency and Test-Retest Reliability

Table 3 shows the results of the reliability analyses. Inter-item correlations for the combined sample ranged from $r=.31$ to .77 , with an average inter-item correlation of $r=.53$. Itemtotal correlations ranged from $r=.52$ to .84 . Cronbach's $\alpha$ for the DAQ total score was excellent in all studies, $\alpha=.94$ to 97. We also calculated McDonald's coefficient omega for the total sample, which was also excellent, $\Omega=.95$. Test-retest reliability (Study 3, 7 days) was high, $r=.87, p<.001$. Thus, reliability was very good and in accord with recommended guidelines (Clark and Watson 1995).

\section{Construct Validity}

Table 4 shows the correlations of the DAQ with related cognitive, symptom and self-esteem measures. In Study 3, the DAQ showed high correlations with the ASQ subscale for negative events, $r=.72, p<.001$, but not with the positive event subscale, $r=-.12, p=.294$. The DAQ correlated with the BDI with $r=.79$, and the ASQ negative event subscale also correlated with the BDI, $r=.60, p<.001$, whereas the ASQ positive event subscale did not correlate significantly with the BDI, $r=-.06, p=.625$. Studies 1 and 2 showed that the DAQ correlated significantly with the Short Hopelessness Scale, $r{ }^{\prime}=.52$ and .59 , respectively, $p{ }^{\prime}<.001$, and correlated negatively with the Self-esteem Scale, $r=-.67$ and $-.69, p s<.001$. Thus, the DAQ showed the expected pattern of high correlations with depression severity and related cognitive and self-esteem measures.

Table 2 Summary of exploratory factor analysis results: explained factorial variance and model fit indices of the Depressogenic Attribution Questionnaire (16 item version) for the total sample

\begin{tabular}{|c|c|c|c|c|c|c|c|c|c|c|}
\hline \multirow[t]{2}{*}{ Model } & \multicolumn{3}{|c|}{$\begin{array}{l}\% \text { Explained variance/ } \\
\text { Eigenvalue }\end{array}$} & \multirow[t]{2}{*}{$\chi^{2}$} & \multirow[t]{2}{*}{$\mathrm{df}$} & \multirow{2}{*}{$\begin{array}{l}\text { Tucker- } \\
\text { Lewis } \\
\text { Index } \\
\text { (TLI) }\end{array}$} & \multirow{2}{*}{$\begin{array}{l}\text { Comparative } \\
\text { Fit Index } \\
(\mathrm{CFI})\end{array}$} & \multirow{2}{*}{$\begin{array}{l}\text { Akaike's } \\
\text { Information } \\
\text { Criterion } \\
\text { (AIC) }\end{array}$} & \multirow{2}{*}{$\begin{array}{l}\text { Root mean square error } \\
\text { of approximation } \\
\text { (RMSEA) }\end{array}$} & \multirow{2}{*}{$\begin{array}{l}\text { Standardised Root } \\
\text { Mean Square } \\
\text { Residual (RMSR) }\end{array}$} \\
\hline & Factor1 & Factor2 & Factor3 & & & & & & & \\
\hline $\begin{array}{c}\text { One-factor } \\
\text { Model }\end{array}$ & $56.0 / 9.52$ & - & - & 340.84 & 119 & .91 & .92 & 11282.08 & .09 & .04 \\
\hline $\begin{array}{c}\text { Two-factor } \\
\text { Model }\end{array}$ & $56.0 / 9.52$ & $5.38 / .91$ & - & 236.25 & 103 & .94 & .95 & 11209.48 & .07 & .03 \\
\hline $\begin{array}{l}\text { Three } \\
\text { Factor } \\
\text { Model }\end{array}$ & $56.0 / 9.52$ & $5.38 / .91$ & $\begin{array}{r}4.78 / \\
.81\end{array}$ & 203.98 & 88 & .94 & .96 & 11207.22 & .07 & .02 \\
\hline
\end{tabular}

Exploratory factor analyses were conducted with MPlus, specifying the respective number of factors, without prespecifying respective items of each of the factors 
Table 3 Scale reliability indices and differences between participants with and without major depression for the Depressogenic Attribution Questionnaire (16 item version) for Studies 1 to 3 and the combined sample

\begin{tabular}{|c|c|c|c|c|c|c|c|}
\hline \multirow[t]{2}{*}{ Sample } & \multicolumn{2}{|l|}{ Reliability indices } & \multirow[b]{2}{*}{$\begin{array}{l}\text { Retest } \\
\text { reliability }\end{array}$} & \multirow[b]{2}{*}{$\begin{array}{l}\text { Total } \\
\text { sample } \\
\text { Mean (SD) }\end{array}$} & \multicolumn{2}{|c|}{ Group differences } & \multirow[b]{2}{*}{$\begin{array}{l}\text { Statistical group } \\
\text { difference }\end{array}$} \\
\hline & $\begin{array}{l}\text { Internal consistency } \\
\text { Cronbach's } \alpha\end{array}$ & $\begin{array}{l}\text { Mean inter-item } \\
\text { correlation } \\
\text { Mean (Min; } \\
\text { Max) }\end{array}$ & & & $\begin{array}{l}\text { Major } \\
\text { depression } \\
\text { Mean (SD) }\end{array}$ & $\begin{array}{l}\text { No major } \\
\text { depression } \\
\text { Mean (SD) }\end{array}$ & \\
\hline \multirow[t]{3}{*}{ Study 1} & \multirow[t]{3}{*}{.94} & \multirow[t]{3}{*}{$.50(.28 ; .78)$} & \multirow[t]{3}{*}{ NA } & \multirow[t]{3}{*}{$\begin{array}{l}18.13 \\
\quad(14.20)\end{array}$} & $\begin{array}{l}\text { Concurrent: } \\
27.61(13.65)\end{array}$ & $15.70(13.32)$ & $F(1,209)=27.05^{* * *}$ \\
\hline & & & & & \multicolumn{2}{|c|}{ Prediction of diagnosis at 6 months: } & \\
\hline & & & & & $30.85(17.75)$ & $15.27(11.887)$ & $F(1,195)=39.52 * * *$ \\
\hline Study 2 & .94 & $.51(.14 ; .81)$ & NA & $\begin{array}{l}20.47 \\
\quad(14.46)\end{array}$ & $33.32(15.46)$ & $16.04(11.25)$ & $F(1,72)=27.27 * * *$ \\
\hline Study 3 & .97 & $.64(.36 ; .88)$ & $.87 * * *$ & $\begin{array}{l}24.44 \\
\quad(16.16)\end{array}$ & $39.00(15.34)$ & $17.30(10.99)$ & $F(1,77)=52.00 * * *$ \\
\hline $\begin{array}{l}\text { Combined } \\
\text { sample }\end{array}$ & .95 & $.53(.31 ; .77)$ & NA & $\begin{array}{l}20.52 \\
\quad(15.59)\end{array}$ & $35.25(17.47)$ & $16.20(11.99)$ & $F(1,147)=123.22 * * *$ \\
\hline
\end{tabular}

${ }^{*} p<.05, * * p<.01, * * * p<.001$

$N A$ not assessed in this study

\section{Discriminant Validity}

As shown in Table 3, the DAQ distinguished between participants with and without concurrent major depression (studies 1-3), and between participants with and without depression at 6 month follow-up (study 1). In all three studies, those with major depression had significantly higher DAQ scores, all $p$ 's $<.001$.

\section{Predictive Validity}

The DAQ correlated with concurrent depression severity (BDI) in all studies, $r$ 's between .69 and .79 (Table 4). It also correlated with PTSD symptom severity (PDS), $r$ 's between .56 and .58 .

In Study 1, DAQ scores at 2 weeks significantly predicted BDI scores at 6-month follow-up, $r=.50, p<.001$. The DAQ also predicted SCID diagnoses of major depression at follow-up, over and above what could be predicted by initial depression symptom severity (BDI). In a logistic regression analysis, initial BDI scores were entered in a first step and significantly predicted depression caseness at 6 months, $\beta=.10, \chi^{2}=30.70$, Nagelkerke's $R^{2}=.26$. The DAQ total score was entered in Step 2 and significantly improved the prediction, over and above initial BDI, $\beta=.04, \chi^{2}=4.97$, Nagelkerke's $R^{2}=.30$. In study 3 , the DAQ score predicted depression diagnosis over and above what could be predicted from the positive and negative ASQ scores $(O R=1.10,95 \% C I=1.04-1.16, p=.001)$.

Participants were also classified into high versus low depressogenic attributional style, defined by a cut-off score above or below 18 (based on the mean DAQ total score in Study 1 of $M=18.12, S D=14.20)$. Participants who endorsed depressogenic attributions above the cut-off of
Table 4 Correlations between the DAQ total score and symptom scores, related cognitive measures, and demographic characteristics $^{\mathrm{a}}$

${ }^{\mathrm{a}} 1=$ male, 2 = female

${ }^{*} p<.05, * * p<.01, * * * p<.001$

$N A$ not assessed in this study, $B D I$ Beck Depression Inventory, PDS Posttraumatic Stress Diagnostic Scale; socio-economic status $=$ score range $1-4$, coded depending on combined household income per year: $1=$ less than $£ 10,000,2=£ 10,000$ $20,000,3=20,000-40,000,4=$ over $£ 40,000$ ); ethnic group: $0=$ Non-Caucasian, 1 = Caucasian

\begin{tabular}{lllll}
\hline & Measure & Study 1 & Study 2 & Study 3 \\
\hline Concurrent symptom measures & Depression (BDI) & $.69 * * *$ & $.63^{* * *}$ & $.79^{* * *}$ \\
& Posttraumatic Stress (PDS) & $.58^{* * *}$ & $.56^{* * *}$ & $.58^{* * *}$ \\
Related cognitive measures & Attributional Styles (ASQ) & & & \\
& Negative events & $\mathrm{NA}$ & $\mathrm{NA}$ & $.72^{* * *}$ \\
& Positive events & $\mathrm{NA}$ & $\mathrm{NA}$ & -.12 \\
& Short Hopelessness Scale & $.59^{* * *}$ & $.52^{* * *}$ & $\mathrm{NA}$ \\
& Self-esteem Scale & $-.67^{* * *}$ & $-.69^{* * *}$ & $\mathrm{NA}$ \\
Intelligence & NART & $-.21^{*}$ & $-.29^{*}$ & -.08 \\
Demographics & Sex & .10 & .18 & -.03 \\
& Age & .02 & -.20 & $.25 *$ \\
& Number of traumatic life events & $.36^{* * *}$ & .13 & $.43^{* * *}$ \\
& Socio-economic status & $.14^{*}$ & $-.23^{*}$ & -.05 \\
& Ethnic group & -.03 & $-.24^{*}$ & -.01 \\
\hline
\end{tabular}


$(n=90)$ were 7 times more likely to develop depression at 6 months compared to those with lower DAQ scores $(n=121)$, $O R=7.29,95 \% C I=2.98-17.86, p<.001$.

\section{Correlations with Demographic Characteristics}

As shown in Table 4, the DAQ total score did not correlate with sex. It showed a small correlation with age in Study 3, $r=.25$, but not in the other studies. There was also a small negative correlation with verbal intelligence as measured by the NART in Study 1 and 2,r=-.21 and $r=-.29$, respectively, but not in Study 3. In Studies 1 and 3, but not Study 2, it showed moderate correlations with the number of traumatic events the participants had experienced, $r$ 's $=.36$ and .43 , respectively. Finally, participants with lower socioeconomic status in Studies 1 and 2, $r=-.14$ and -.23 , respectively, and Non-Caucasians in Study 3, $r=-.24$, tended to endorse more depressogenic attributions. Note, however, that when Bonferroni correction is applied to control for the familywise error rate of conducting these sets of correlations (adjusted $p=.002$ ), only the correlations with number of traumatic events remained significant.

\section{Completion Time and Participant Feedback on DAQ and ASQ}

The mean time it took participants to complete the DAQ was $M=2.36 \mathrm{~min}, S D=1.15$; and for the ASQ $M=$ $17.32 \mathrm{~min}, S D=7.73$ (Study 3). Repeated measures ANOVAs for completion times with the between subject factor Diagnosis (major depression versus no depression) and measure (DAQ versus ASQ) as within subject factor showed a main effect of measure, $F(1,71)=$ 305.44, $p<.001$, with shorter completion times for the DAQ than the ASQ for both depressed and non-depressed participants, but no main effect of diagnosis, $F(1,71)=$ $1.29, p=.261$, and no significant interaction, $F(1,71)=$ $1.39, p=.242$. Participants rated the ASQ as more difficult to complete than the DAQ, DAQ: $M=2.51, S D=1.69$, ASQ: $M=5.29, S D=2.40$ (Study 3). The ANOVA showed a main effect of measure type, $F(1,76)=109.55, p<.001$, with higher difficulty rating for the ASQ compared to the DAQ given by both depressed and non-depressed participants. Again, there was no significant effect of diagnosis, $F(1,76)=2.17, p=.145$, and no significant interaction, i.e., both the depressed and nondepressed groups reported that the DAQ was easier to fill in than the ASQ.

The mean number of ASQ situations for which participants were able to retrieve personal memories was $7.36, S D=2.30(61 \%)$; there was no difference between depressed and nondepressed participants, $F(1$, $75)=2.29, p=.135$. Participants specified some difficulties encountered during completion of the ASQ, but not the
DAQ. Answers included (i) difficulties relating to the scenarios, i.e., imagining the situations or imagining themselves in the situations (38\% of participants), (ii) difficulties identifying and specifying the attributional process, i.e., identifying a cause at all, or choosing just one cause $(27 \%)$, (iii) general difficulties in thinking $(8 \%)$, i.e., having to think twice, changing their mind, or analyzing their own thoughts. More detailed results are available from the authors upon request.

\section{Discussion}

A pessimistic attributional style, the tendency to attribute negative events to internal, stable and global causes, is a vulnerability factor for depression (Peterson and Seligman 1984; Sweeney et al. 1986; Gladstone and Kaslow 1995). We developed and validated the Depressive Attributions Questionnaire (DAQ), a new short questionnaire designed to measure depressogenic attributions in clinical settings. The DAQ showed excellent internal consistency and testretest reliability, and thus met standards for reliable measures (e.g., DeVellis 1991). High correlations with the negative event subscale of the Attributional Style Questionnaire (ASQ; Peterson et al. 1982), and measures of hopelessness and self-esteem supported the DAQ's construct validity. The DAQ correlated highly with selfreports of depression (BDI), discriminated between participants with and without major depression, and predicted depression over and above the ASQ total score. In line with the hopelessness theory of depression (Abramson et al. 1989), the DAQ predicted clinician-rated major depression at 6 months after an uncontrollable stressful event, over and above what could be explained by initial depression symptoms at 2 weeks. Overall, these preliminary results suggest that the DAQ may be a useful measure of depressogenic attributions, which is easy to administer, well accepted by patients and predictive of future depression.

The results also confirmed that the most commonly used measure of a pessimistic attributional style, the ASQ (Peterson et al. 1982) correlated highly with self-reported depression (BDI) when the negative event subscale was used. The positive event subscale, however, did not significantly correlate with depression, which is in accord with previous findings that attributional style for positive events is less strongly associated with depression onset than attributional style for negative events (Sweeney et al. 1986). The DAQ refers mainly to negative events, which explains its high correlation with the ASQ negative event subscale and the lack of a significant correlation with the positive event subscale. Study 3 showed that the ASQ did not have advantages over the DAQ in predicting depression 
and took longer to complete. In line with previous reports suggesting that the ASQ can be time-consuming and may be difficult to complete without close supervision (Dykema et al. 1996), participants in Study 3 found the DAQ easier to complete than the ASQ. The DAQ may thus have advantages over the ASQ in clinical settings. However, it lacks the possible advantage of priming causal attributions directly by presenting specific hypothetical scenarios, as in the ASQ, which may be important for some research questions. However, the DAQ's answer format may also be a strength for clinical applications as depressed patients often have problems generating specific memories (Williams et al. 2003) and may find it easier to respond to general statements about themselves than to generate specific causes for hypothetical events.

Previous measures of pessimistic attributions, such as the ASQ or the CSQ, have been shown to be valid predictors of risk for depression (Peterson et al. 1982; Haeffel et al. 2008; Bruder-Mattson and Hovanitz 1990). The results for the DAQ are in line with the predictive validity of pessimistic attributions. In accord with the reformulated helplessness theory (Abramson et al. 1989), participants in Study 1 who endorsed pessimistic attributions above the sample mean were seven times more likely to develop depression at 6 months post-trauma than those who endorsed pessimistic attributions below the mean. ${ }^{1}$ Future studies will need to determine an optimal cut-off score in larger samples.

If the results are cross-validated, the DAQ may offer an efficient way of screening for risk of depression. In Study 3, depressed and non-depressed participants took less than 3 min to complete the DAQ so that it appears suitable for primary care and other relevant settings. If independent evaluations support its predictive validity, the DAQ could be used to identify individuals vulnerable to depression who could then be offered prevention programs. A recent study in Iceland, for instance, used a 48-item Childrens Attributional Style Questionnaire to identify "at risk" adolescents who were then assigned to a prevention programme; a procedure that proved successful in reducing initial episodes of depression in this group (Arnarson and Craighead 2009). Such screening and prevention programmes based on pessimistic attributional style may save considerable costs in the long-term as depression is currently one of the most prevalent and costly health conditions worldwide (e.g., WHO 2008; Kessler et al. 2007). The DAQ may also be of use as a process measure in treatment settings, for

\footnotetext{
${ }^{1}$ Note that the DAQ's validity for predicting depression at follow-up could not be directly compared to the performance of the ASQ, as only the DAQ, but not the ASQ, was employed in the longitudinal study (study 1).
}

example, to track changes in attributional style over the course of therapy or as a measure of a potential mechanism of therapeutic change.

Although we employed the DAQ in three independent studies with a reasonably large combined sample, used structured clinical interviews to establish depression diagnoses, and followed participants in Study 1 for 6 month following a stressful life event, limitations should be noted. First, confirmatory factor analyses should be conducted in a larger sample in order to cross-validate and confirm the DAQ's one-factorial structure. Our DAQ factor analyses strongly suggested a one-factor solution, but some authors have noted that the three attributional dimensions may not have equal status, i.e., stability and globality may have a more direct relationship to depression than the internality subscale (Abramson et al. 1989). This suggestion could be tested in future studies using DAQ subscales. Factor analyses including the DAQ, as well as the ASQ and the BDI should also be performed to inspect joint loading patterns. We could not perform these analyses as DAQ and ASQ were only employed together in the relatively small sample of study 3. Relatedly, longer-test-retest intervals are desirable, and the DAQ should be reassessed months, rather than 1 week following the baseline assessment. Second, further studies are needed to determine the optimal DAQ cut-off for the prediction of later depression. A third and more general issue concerns the question of whether pessimistic attributional style can be directly assessed by self-report or whether implicit measures are more suitable to capture such cognitive processes. Some theorists have described cognitive vulnerabilities as cognitive frameworks that are latent, outside of awareness, and are activated by stress (e.g., Scher et al. 2005). Self-report questionnaires such as the DAQ are not suited for measuring cognitive vulnerabilities that largely operate outside of awareness, and implicit tasks, such as priming tasks, may be needed to assess them. However, these have practical limitations as they are time-consuming and impractical to administer outside the laboratory. Fourth, the present study only employed the ASQ, further studies should compare the DAQ with other measures of attributional style, such as the CSQ. Finally, the DAQ consists mainly of items relating to negative events (e.g., 'When bad things happen, I think it is my fault') and incorporated only 3 positive statements (e.g., When things go well, I think it is just due to good luck'), all chosen as a result of expert clinician feedback and relevance ratings. Like some previous research, the present data suggest that attributions of negative events may be more predictive of depression than those of positive events (Sweeney et al. 1986). Future research is nevertheless needed to determine whether including more items about positive events could enhance predictive validity of the DAQ. 
In conclusion, our data indicate that the DAQ is a valid, reliable and efficient way of assessing pessimistic attributions predictive of depression. The DAQ was generally completed in less than $5 \mathrm{~min}$, and was well accepted by non-clinical and clinical participants. Hence, it may be suitable for use in clinical and research settings with time constraints, where personal support may not always be available and easy administration and scoring are crucial. In such settings, the DAQ may provide a convenient way of indexing attributional style. The DAQ is not meant to replace commonly used and well-established research instruments, such as the ASQ, or the CSQ. However, it may provide useful for screening for depression vulnerability in primary care, treatment studies, or research settings with limited amount of allocated time.

\section{Appendix}

Items of the Depressogenic Attribution Questionnaire (DAQ), with attribution domain, \% of participants who endorsed the item, and factor loading (one-factorial model) ${ }^{1}$

\begin{tabular}{|c|c|c|c|c|c|}
\hline & Item & Attribution Domain & Mean (SD) & $\begin{array}{l}\% \text { Participants endorsed } \\
\quad \text { (item score greater than 1) }\end{array}$ & $\begin{array}{l}\text { Factor loading } \\
\text { (one-factorial model) }\end{array}$ \\
\hline 1. & $\begin{array}{l}\text { When bad things happen, I } \\
\text { think it is my fault }\end{array}$ & I & $1.3(1.22)$ & 71.6 & .66 \\
\hline 2. & $\begin{array}{l}\text { I feel helpless when bad things } \\
\text { happen. }\end{array}$ & $\mathrm{H}$ & $1.61(1.28)$ & 77.9 & .74 \\
\hline 3. & $\begin{array}{l}\text { When things do not go well, I } \\
\text { get easily discouraged }\end{array}$ & $\mathrm{H}$ & $1.63(1.28)$ & $85 \%$ & .76 \\
\hline 4. & $\begin{array}{l}\text { When things go well, I think it } \\
\text { is just due to good luck }\end{array}$ & I & $1.54(1.29)$ & 72.9 & .57 \\
\hline 5. & $\begin{array}{l}\text { When something I do goes } \\
\text { wrong, I think it is because I } \\
\text { am incapable }\end{array}$ & I & $1.23(1.26)$ & 63.8 & .74 \\
\hline 6. & $\begin{array}{l}\text { When something good happens, } \\
\text { I think it will not } \\
\text { last long. }\end{array}$ & $\mathrm{S}$ & $1.48(1.34)$ & 68.7 & .77 \\
\hline 7. & $\begin{array}{l}\text { When something bad happens, } \\
\text { I think there is little I can do } \\
\text { to make things better. }\end{array}$ & $\mathrm{H}$ & $1.29(1.24)$ & 64.6 & .77 \\
\hline 8. & $\begin{array}{l}\text { When something good happens } \\
\text { to me, I think this was } \\
\text { because of other people or the } \\
\text { circumstances rather than me. }\end{array}$ & I & $1.26(1.23)$ & 63.7 & .78 \\
\hline 9. & Bad things always happen to me. & G & $1.06(1.29)$ & 50.4 & .79 \\
\hline 10. & $\begin{array}{l}\text { When bad things happen, I rely } \\
\text { on other people to sort things out. }\end{array}$ & $\mathrm{H}$ & $.75(.99)$ & 47.6 & .59 \\
\hline 11. & $\begin{array}{l}\text { When bad things happen to me, I } \\
\text { am sure it will happen again. }\end{array}$ & $\mathrm{S}$ & $1.01(1.18)$ & 55.4 & .82 \\
\hline 12. & $\begin{array}{l}\text { When bad things happen to me, } \\
\text { I think my life will never get } \\
\text { better. }\end{array}$ & $\mathrm{S}$ & $.96(1.26)$ & 46.6 & .86 \\
\hline 13. & $\begin{array}{l}\text { When something bad happens, I } \\
\text { think of the problems this will } \\
\text { cause in all areas of my life. }\end{array}$ & G & $1.54(1.29)$ & 75.7 & .72 \\
\hline 14. & $\begin{array}{l}\text { Bad things happen in all areas } \\
\text { of my life. }\end{array}$ & G & $.99(1.26)$ & 47.8 & 78 \\
\hline 15. & $\begin{array}{l}\text { When bad things happen to me, } \\
\text { I can't see anything positive } \\
\text { in my life. }\end{array}$ & $\mathrm{S}$ & 1.09 (1.31) & 52.8 & .87 \\
\hline 16. & $\begin{array}{l}\text { When bad things happen, } \\
\text { nothing seems to be in place } \\
\text { any more. }\end{array}$ & G & $1.20(1.27)$ & 61.8 & .82 \\
\hline
\end{tabular}

Note: $\mathrm{I}=$ Internal attribution of negative event and external attribution of positive events, $\mathrm{S}=$ Stable cause of negative events, $\mathrm{G}=$ global attribution of negative events, $\mathrm{H}=$ Perceived helplessness

${ }^{1}$ As suggested by our analyses, the 1-factor model outperformed the 2- and 3-factor model of the DAQ items. For reasons of brevity, information on the latter two models are thus not represented on an item-basis in this paper. This information is available from the first author upon request, including the standardized regression coefficients in the pattern matrix for all DAQ items in both solutions, communality estimates, percentages of common and total variance. 
Open Access This article is distributed under the terms of the Creative Commons Attribution Noncommercial License which permits any noncommercial use, distribution, and reproduction in any medium, provided the original author(s) and source are credited.

\section{References}

Abramson, L. Y., Seligman, M. E. P., \& Teasdale, J. (1978). Learned helplessness in humans: critique and reformulation. Journal of Abnormal Psychology, 87, 49-74. doi:10.1037/0021-843X.87.1.49.

Abramson, L. Y., Metalsky, G. I., \& Alloy, L. B. (1989). Hopelessness depression: a theory-based subtype of depression. Psychological Review, 96, 358-372. doi:10.1037/0033-295X.96.2.358.

Abramson, L. Y., Alloy, L. B., Hogan, M. E., Whitehouse, W. G., Cornette, M., Akhavan, S., et al. (1998). Suicidality and cognitive vulnerability to depression among college students: a prospective study. Journal of Adolescence, 21, 473-487. doi:10.1006/jado.1998.0167.

Alloy, L. B., Abramson, L. Y., Whitehouse, W. G., Hogan, M. E., Panzarella, C., \& Rose, D. T. (2006). Prospective incidence of first onsets and recurrences of depression in individuals at high and low cognitive risk for depression. Journal of Abnormal Psychology, 115, 145-156. doi:10.1037/0021843X.115.1.145.

Anderson, C. A., \& Riger, A. L. (1991). A controllability attributional model of problems in living: dimensional and situational interactions in the prediction of depression and loneliness. Social Cognition, 9(2), 149-181.

Arnarson, E., \& Craighead, W. E. (2009). Prevention of depression among Icelandic adolescents. Behaviour Research and Therapy, 47, 577-585. doi:10.1016/j.brat.2009.03.011.

Beck, A. T. (1967). Depression: Clinical, experimental and theoretical aspects. New York: Harper \& Row.

Beck, A. T., \& Steer, R. A. (1987). Beck Depression Inventory: Manual. San Antonio: Psychological Corporation.

Beck, A. T., \& Steer, R. A. (1988). Manual for the Beck Hopelessness Scale. San Antonio: Psychological Corporation.

Beck, A. T., Rush, A. J., Shaw, B. F., \& Emery, G. (1979). Cognitive therapy of depression. New York: Guilford Press.

Bollen, K. A. (1989). Structural equations with latent variables. New York: Wiley.

Bruder-Mattson, S. F., \& Hovanitz, C. A. (1990). Coping and attributional styles as predictors of depression. Journal of Clinical Psychology, 46, 557-565. doi:10.1002/1097-4679 (199009)46:5<557::aid-jclp2270460503>3.0.co;2-1

Clark, L. A., \& Watson, D. (1995). Constructing validity: Basic issues in objective scale development. Psychological Assessment, 7, 309-319. doi:10.1037/1040-3590.7.3.309.

Crawford, J. R., Parker, D. M., Allan, K. M., Jack, A. M., \& Morrison, F. M. (1991). The Short NART: cross-validation, relationship to IQ and some practical considerations. The British Journal of Clinical Psychology, 30(3), 223-229.

DeVellis, R. F. (1991). Scale development: Theory and application. Newbury Park: Sage.

Dykema, J., Bergbower, K., Doctora, J. D., \& Peterson, C. (1996). An attributional style questionnaire for general use. Journal of Psychoeducational Assessment, 14, 100-108. doi:10.1177/ 073428299601400201.

Feather, N. T., \& Tiggemann, M. (1984). A balanced measure of attributional style. Australian Journal of Psychology, 36, 276283. doi:10.1080/00049538408255096.
First, M. B., Spitzer, R. L., Gibbon, M., \& Williams, J. B. W. (1996). Structured clinical interview for DSM-IV axis I disorders. Washington, D.C.: American Psychiatric Press.

Foa, E. B., Cashman, L., Jaycox, L., \& Perry, K. (1997). The validation of a self-report measure of posttraumatic stress disorder: the Posttraumatic Diagnostic Scale. Psychological Assessment, 9, 445-451. doi:10.1037/1040-3590.9.4.445.

Gibb, B. E., Alloy, L. B., Abramson, L. Y., Rose, D. T., Whitehouse, W. G., \& Hogan, M. E. (2001). Childhood maltreatment and college students' current suicidal ideation: a test of the hopelessness theory. Suicide \& Life-Threatening Behavior, 31, 405-415. doi:10.1521/suli.31.4.405.22042.

Gladstone, T. R., \& Kaslow, N. J. (1995). Depression and attributions in children and adolescents: a meta-analytic review. Journal of Abnormal Psychology, 23, 597-606. doi:10.1007/BF01447664.

Haeffel, G. J., Gibb, B. E., Metalsky, G. I., Alloy, L. B., Abramson, L. Y., Hankin, B. L., et al. (2008). Measuring cognitive vulnerability to depression: development and validation of the cognitive style questionnaire. Clinical Psychology Review, 28, 824-836. doi:10.1016/j.cpr.2007.12.001.

Halligan, S. L., Michael, T., Clark, D. M., \& Ehlers, A. (2003). Posttraumatic stress disorder following assault: the role of cognitive processing, trauma memory, and appraisals. Journal of Consulting and Clinical Psychology, 71, 419-431. doi:10.1037/0022-006X.71.3.419.

Hilsman, R., \& Garber, J. (1995). A test of the cognitive diathesisstress model of depression in children: academic stressors, attributional style, perceived competence, and control. Journal of Personality and Social Psychology, 69, 370-380. doi:10.1037/ 0022-3514.69.2.370.

Kessler, R. C., Merikangas, K. R., \& Wang, P. S. (2007). Prevalence, comorbidity, and service utilization for mood disorders in the United States at the beginning of the twenty-first century. Annual Review of Clinical Psychology, 3, 137-158. doi:10.1146/annurev. clinpsy.3.022806.091444.

Kleim, B., Ehlers, A., \& Glucksman, E. (2007). Early predictors of chronic post-traumatic stress disorder in assault survivors. Psychological Medicine, 37, 1457-1467. doi:10.1017/ S0033291707001006.

Kline, R. B. (1998). Principles and practice of structural equation modeling. New York: Guilford Press.

Kubany, E. S., Haynes, S. N., Leisen, M. B., Owens, J. A., Kaplan, A. S., Watson, S. B., et al. (2000). Development and preliminary validation of a brief broad-spectrum measure of trauma exposure: the Traumatic Life Events Questionnaire. Psychological Assessment, 12, 210-224. doi:10.1037/1040-3590.12.2.210.

Nelson, H. (1991). National Adult Reading Test (NART). Test Manual. Windson, NFER-Nelson.

Norman, P. D., \& Antaki, C. (1988). Real events attributional style questionnaire. Journal of Social and Clinical Psychology, 7(2-3), 97-100.

Peterson, C., \& Seligman, M. E. P. (1984). Causal explanations as a risk factor for depression: theory and evidence. Psychological Review, 91, 347-374. doi:10.1037/0033-295X.91.3.347.

Peterson, C., \& Villanova, P. (1988). An expanded Attributional Style Questionnaire. Journal of Abnormal Psychology, 97, 87-89. doi:10.1037/0021-843X.97.1.87.

Peterson, C., Semmel, A., von Baeyer, C., Abramson, L. Y., Metalsky, G. I., \& Seligman, M. E. P. (1982). The Attributional Style Questionnaire. Cognitive Therapy and Research, 6, 287-300. doi:10.1007/BF01173577.

Rosenberg, M. (1989). Society and the adolescent self-image. Revised edition. Middletown: Wesleyan University Press. 
Scher, C. D., Ingram, R. E., \& Segal, Z. V. (2005). Cognitive reactivity and vulnerability: empirical evaluation of construct activation and cognitive diatheses in unipolar depression. Clinical Psychology Review, 25, 487-510. doi:10.1016/j.cpr.2005.01.005.

Seligman, M. E. (1978). Learned helplessness as a model of depression. Comment and integration. Journal of Abnormal Psychology, 87, 165-179. doi:10.1037/0021-843X.87.1.49.

Sweeney, P. D., Anderson, K., \& Bailey, S. (1986). Attributional style in depression: a meta-analytic review. Journal of Personality and Social Psychology, 50, 974-991. doi:10.1037/0022-3514.50.5.974.

Voelz, Z. R., Haeffel, G. J., Joiner, T. E., \& Dineen Wagner, K. (2003). Reducing hopelessness: the interaction of enhancing and depressogenic attributional style for positive and negative life events among youth psychiatric inpatients. Behavior Research and Therapy, 41, 1183-1198. doi:10.1016/S00057967(03)00030-5.

WHO, Disorders management, Depression (2008), accessed online at www.who.int, on January 21, 2008.

Williams, J. M. G. (2003). Hopelessness Scale. Unpublished manuscript.

Williams, J. M. G., Barnhofer, T., Crane, C., Hermans, D., Raes, F., Watkins, E., et al. (2003). Autobiographical memory specificity and emotional disorder. Psychological Bulletin, 133, 122-148. doi:10.1037/0033-2909.133.1.122. 